\title{
Sala invertida em avaliações de físico química no ensino superior
}

\author{
Josimara Cristina de Carvalho Oliveira
}

André Camargo de Oliveira

\section{Resumo}

Esse trabalho descreve um relato de experiência de sala de aula onde o recurso didático da sala invertida foi usado para ministrar os conteúdos de cinética química, equilíbrio químico e eletroquímica em uma turma de 17 acadêmicos do Curso de Licenciatura em Química noturno, da Universidade Estadual de Roraima - UERR Campus Rorainópolis em 2015. As sequências de atividades foram elaboradas, testadas e avaliadas a fim de melhorar os processos de ensino e de aprendizagem e sanar o baixo rendimento dos acadêmicos em Físico-Química. Os resultados foram satisfatórios mostrando que os acadêmicos modificaram a forma de estudar, montaram grupos de estudos, passaram a utilizar os livros universitários e artigos da área de ensino de química, apresentaram melhor rendimento nas avaliações, se mostraram mais motivados e participativos, utilizaram os conhecimentos aprendidos em seus estágios supervisionados no Ensino Médio, desenvolveram autocrítica e aprenderam a receber críticas de forma mais construtiva.

Palavras-Chave: Cinética Química. Equilíbrio Químico. Eletroquímica. Formação Docente. 


\title{
Reverse room in chemical physics evaluations in higher education
}

\author{
Josimara Cristina de Carvalho Oliveira \\ André Camargo de Oliveira
}

\section{Abstract}

This work describes a classroom experience report where the didactic resource of the flipped classroom was used to teach the contents of chemical kinetics, chemical equilibrium and electrochemistry in a class of 17 academics from the night Chemistry Degree Course State University de Roraima - UERR Campus Rorainópolis in 2015. The activity sequences were elaborated, tested, and evaluated to improve the teaching and learning processes and remedy the low performance of academics in Physical Chemistry. The results were very satisfactory showing that academics changed the way of studying, set up study groups, started to use university books and articles in the area of teaching chemistry, showed better performance in evaluations, were more motivated and participatory, used the knowledge learned in their supervised stages in high school, developed self-criticism and learned to receive criticism in a more constructive way.

Keywords: Chemical kinetics. Chemical balance. Electrochemistry. Teacher Formation. 


\section{Introdução}

Desde 2007 (CARVALHO-OLIVEIRA; OLIVEIRA, 2012) observa-se que licenciandos de química da UERR Rorainópolis apresentam defasagem em Língua Portuguesa, Química, Matemática e Física. Esse fato contribuiu para o baixo rendimento deles nas avaliações por conta das dificuldades na interpretação de textos e cálculos matemáticos exigidos em físicoquímica. Além de inibição quando se dirigiam ao professor ou ao quadro e o hábito da memorização sem a compreensão dos conceitos. Os acadêmicos precisavam aprender a raciocinar, a usar a lógica, a unir os diversos conceitos vistos ao longo da vida escolar para perder a insegurança.

Com base nas observações feitas em uma turma do referido curso entre 2014 e 2015, elaborou-se uma sequência de atividades, para os conteúdos programados da disciplina de físico-química II, em acordo com os estudantes, a fim de motivá-los a estudar, melhorar o entendimento dos conceitos e o rendimento nas avaliações.

De acordo com o diagnóstico, o problema da pesquisa esteve apoiado na questão de como incentivar a leitura e o estudo a fim de melhorar o processo de ensino e aprendizagem em físico-química. Para responder o problema da pesquisa, foram elaboradas, aplicadas e analisadas qualitativamente algumas atividades envolvendo ações importantes para o fortalecimento das habilidades e competências dos estudantes, como: diálogo, debate, trabalho em equipe, pesquisa, elaboração de aula, socialização, cooperatividade, ética, autoavaliação.

O recurso didático usado foi o da Sala de Aula Invertida que é uma abordagem híbrida de ensino onde a aquisição das informações ocorre fora da sala de aula por meio de leituras diversas, videoaulas etc. e o tempo de sala de aula é usado para a prática, sob a supervisão do professor. Além disso, não existe um modelo pronto de sala invertida, sendo preciso adaptar a sala de aula conforme a realidade de cada turma e cada conteúdo (BERGMAN; SAMS, 2017).

\section{Metodologia: Descrição da pesquisa e da amostra}

Essa pesquisa foi realizada pela autora, professora da turma, visando adquirir informações sobre recursos didáticos para auxiliar no processo de aprendizagem na disciplina de Físico-Química. Caracterizou-se como descritiva de acordo com os objetivos, porque se propôs a descrever uma experiência de sala de aula. Quanto aos procedimentos técnicos foi uma pesquisa de campo, pois, consistiu na observação de fatos e fenômenos tal como ocorreram em uma turma de acadêmicos. De acordo com o problema teve uma abordagem qualitativa sem rigor estatístico no tratamento dos dados (PRODANOV e FRETAS, 2013).

Foi desenvolvida com 17 acadêmicos do sexto semestre do Curso de Licenciatura Plena em Química da Universidade Estadual de Roraima - UERR Campus Rorainópolis, no primeiro semestre de 2015. A amostra foi escolhida intencionalmente, uma vez que na disciplina de Físico Química I, ministrada no segundo semestre de 2014, dos 27 acadêmicos 
regularmente matriculados apenas 19 chegaram ao final e somente quatro atingiram média igual ou acima de 70, exigida pela UERR.

A disciplina de Físico-Química II de 72 horas foi dividida em três unidades, contendo uma avaliação por unidade, totalizando 18 aulas de quatro horas cada uma. A cada 24 horas de aula (seis aulas) estava prevista uma avaliação tradicional (escrita) e/ou diferenciada (seminário; experimento; jogo didático; dinâmica em grupo). O conceito final seria a média simples dos valores obtidos nas três unidades.

\section{Primeira Unidade - Sequência proposta inicialmente no Plano de Curso}

O planejamento inicial da disciplina de Físico-Química II foi semelhante ao da FísicoQuímica I com aulas expositivas e dialogadas, listas de problemas, uso do laboratório virtual, avaliação escrita, leitura e discussão por escrito de artigos. O objetivo Geral da disciplina foi: Introduzir os conceitos fundamentais de Cinética Química, Equilíbrio Químico e Eletroquímica, procurando relacioná-los com os eventos do mundo real.

Ao iniciar o ano letivo, foram ministradas 12 horas de aulas teóricas sobre os conteúdos envolvidos em cinética química, utilizando quadro branco, apostila feita com base nos livros didáticos propostos 5 .

Utilizaram-se outras oito horas de aula para corrigir e explicar todos os problemas das listas na sala de aula. A avaliação escrita teve a durabilidade de até quatro horas e continha duas questões, uma dissertativa e uma de cálculo, perfazendo um total de 13 acertos. As perguntas foram elaboradas de acordo com os problemas trabalhados e questionamentos dos estudantes, sendo que a primeira questão envolvia descobrir qual a ordem da reação de decomposição do dióxido de nitrogênio a partir de dados e de uma tabela fornecida no enunciado, justificando a resposta fazendo o gráfico em papel milimetrado, escrevendo a expressão da velocidade da reação, calculando da velocidade média, a constante de velocidade e o tempo de meia vida (equivalia a sete acertos). A segunda era para explicar por que nem sempre as colisões entre as moléculas reagentes levam às reações químicas (equivalia a seis acertos, dentro dos critérios elaborados a partir do conteúdo teórico trabalhado). O valor numérico da avaliação escrita foi obtido por meio de regra de três simples, onde 13 acertos equivaleram a 100 pontos. A avaliação corrigida foi devolvida a cada acadêmico e corrigida no quadro. Essa ação teve a duração de uma hora, totalizando 25 horas para o conteúdo de cinética.

5 ATKINS, P. Físico-química: Fundamentos. 3 ed. Rio de Janeiro: LTC, 2003; ATKINS, P. W.; JONES, L. Princípios de química: Questionando a vida moderna e o meio ambiente. Porto Alegre: Bookman, 3 ed., 2006; BROWN, T. L. et. al. Química: A ciência central. São Paulo: Pearson Education do Brasil, 9 ed., 2005; RUSSELL, John B. Química Geral. São Paulo: McGraw-Hill do Brasil, 2 ed., 2012.

ISSN 2526-2882 
A partir dos resultados insatisfatórios da avaliação, fez-se um debate na sala de aula a fim de propor uma solução para o baixo rendimento da turma, verificada desde o ano anterior, e da dificuldade de entendimento dos conteúdos de físico-química. Assim, a professora elaborou três sequências de atividades onde os acadêmicos sugeriram quais seriam as etapas individuais, em grupo e os prazos. Essa reformulação da primeira unidade só foi possível devido à liberdade que o professor universitário possui na condução das suas disciplinas, mediante a aprovação dos estudantes e o não comprometimento das outras duas unidades. Sendo assim, a Coordenação Acadêmica da UERR foi notificada e a proposta foi aceita.

Assim, os estudantes assumiram boa parte do controle da sala de aula, ministrando aulas teórico-práticas utilizando recursos multimídia, experimentos, jogos didáticos confeccionados por eles e dinâmicas diversas, caracterizando a abordagem metodológica da Sala de aula invertida, onde a responsabilidade da instrução é centrada no aluno, o qual assume a responsabilidade pelo estudo teórico e a aula presencial serve como aplicação prática dos conceitos estudados previamente (JAIME; KOLLER; GRAEML, 2015). As sequências estão descritas a seguir.

\section{Primeira Unidade - Sequência de Atividades 1 para Cinética Química}

Teve como objetivos incentivar os acadêmicos a estudarem o conteúdo de cinética química; treinar a oratória; preparar plano de aula; apresentar o conteúdo teórico para os colegas indicando os pontos de dúvidas e de aprendizado, em comparação com a primeira unidade.

Utilizaram-se outras 14 horas, sendo oito horas em horário oposto, com o consentimento dos acadêmicos, distribuídas da seguinte maneira: 1) cada acadêmico, individualmente, preparou e ministrou uma aula de até 20 minutos sobre o conteúdo de cinética química, de forma resumida, utilizando quadro branco e/ou recurso multimídia, com a entrega de plano de aula por escrito e de uma autoavaliação comentada. A duração: dessa etapa foi de oito horas; 2) Em dupla, prepararam um experimento de cinética química e apresentaram na sala com até 20 minutos de duração, também com a entrega de plano de aula. Essa etapa teve a duração de seis horas e o desafio era reproduzir um experimento retirado de livros ou arquivos da rede e propor alguma modificação no experimento justificando-a; 3) Avaliação escrita (Duração: quatro horas) composta por quatro questões, onde a primeira trazia uma tabela com dados de tempo e concentração de um reagente A em uma reação fictícia, pedindo para calcular a velocidade média no intervalo entre quatro e 14 minutos; a análise e a construção do gráfico da concentração versus o tempo em papel milimetrado, indicando qual a ordem da reação. A segunda questão era a análise de um gráfico em relação a reagentes e produtos formados. A terceira, envolvia a análise de um sistema em diferentes etapas de reação. A quarta fornecia um gráfico da energia versus o caminho da reação e pedia os valores 
da energia de ativação, da entalpia da reação, quais eram os reagentes e os produtos e se a reação era endotérmica ou exotérmica. A seguir os acadêmicos se autoavaliaram usando critérios próprios, entregando um comentário por escrito com os prós e contras da SD. Essa sequência teve a duração de 18 horas em sala de aula.

\section{Segunda Unidade - Sequência 2 para Equilíbrio Químico}

Sendo esse um conteúdo que os acadêmicos ainda desconheciam, o objetivo foi expor a parte teórica acompanhada da resolução de lista de exercícios, a fim de que se familiarizassem com os termos e tópicos para que depois pudessem preparar o plano de aula, o experimento, e ministrar para os colegas.

Essa sequência envolveu: 1) Exposição da parte teórica pela professora da disciplina utilizando recursos multimídia, quadro branco, pincel e os livros propostos (Duração: oito horas); 2) aplicação e correção de duas listas com questões diversificadas (Duração: oito horas); 3) apresentação dos acadêmicos em dupla dos experimentos e entrega do plano de aula (Duração: oito horas); 4) apresentação das aulas teóricas em forma de seminário, com entrega de plano de aula por escrito e autoavaliação (Duração: oito horas); 4) avaliação escrita (Duração: quatro horas) versando sobre todo o conteúdo na forma de exercícios semelhantes aos das listas resolvidas (Princípio de Le Chatelier; cálculo da constante de equilíbrio em relação à concentração e à pressão; análise de gráficos; uma questão aberta para o acadêmico comentar sobre a avaliação); 5) correção da avaliação no quadro (uma hora). Totalizando 37 horas em sala de aula.

\section{Terceira Unidade - Sequência 3 para Eletroquímica}

Essa sequência teve como diferencial a ausência da exposição inicial dos conteúdos teóricos pela professora e os acadêmicos tiveram que ministrar uma aula teórica utilizando um experimento: 1) Apresentação em dupla de até 30 minutos, da aula teórica pelos acadêmicos, acompanhada da apresentação e explicação de um experimento (duração de oito horas), com entrega digital de plano de aula, autoavaliação, discussão sobre os prós e contras da sequência; 2) oito horas de aula teórica ministrada pela professora utilizando recurso multimídia para sanar as dúvidas, onde se utilizaram exemplos diversos e os experimentos apresentados pelas duplas; 3) Avaliação escrita com duração de quatro horas e avaliação geral da proposta. Essa sequência teve a duração de 20 horas em sala de aula.

A avaliação escrita esteve composta por cinco questões, sendo a primeira para desenhar a pilha formada entre zinco e prata indicando todas as etapas e reações; a segunda era para desenhar a eletrólise aquosa para o iodeto de zinco indicando as reações e diferença de potencial; a terceira era para apontar as diferenças entre eletrólise aquosa e ígnea, e entre pilha, bateria e eletrólise; a quarta pedia para observar uma figura que continha um 
experimento e os valores das reações de redução, de oxidação e o potencial, onde o estudante deveria descrever o que estava acontecendo; a quinta era livre para complemento ou opinião.

A coleta e o tratamento dos dados envolveram Análise do Conteúdo, observação participante e sistemática com anotação em diário de campo, registro fotográfico, relato por escrito dos acadêmicos em suas avaliações e autoavaliações e a comparação dos valores obtidos nas avaliações escritas.

A Análise do Conteúdo foi escolhida por ser um conjunto de procedimentos e técnicas capazes de extrair o sentido de um texto por meio de palavras-chave, categorias e temas, a fim de identificar a frequência dessas unidades para fazer inferências e extrair os significados (CHIZZOTTI, 2010), além disso possui uma variedade de formas e pode ser adaptada a um amplo campo de aplicação (BARDIN, 2011, p. 37). Assim, a professora criou critérios envolvendo o conhecimento que os acadêmicos deveriam dominar após o estudo teórico e prático dos conteúdos programados.

\section{Resultados e Discussão: Diagnóstico}

Desde 2007 (CARVALHO-OLIVEIRA e OLIVEIRA, 2012) as turmas do curso de química apresentaram elevado índice de evasão e dificuldades semelhantes, além de possuírem faixa etária heterogênea onde a maior parte era casada, tinha filhos, trabalhava e estudava. Assim, viu-se a necessidade de modificar a forma de ensinar e de avaliar.

Anteriormente muitas estratégias foram usadas pelos professores: aula expositiva e dialogada com resumo no quadro branco e uso de recursos multimídia; contextualização da teoria com exemplos do cotidiano; uso da experimentação com materiais alternativos de baixo custo; uso de apostilas resumidas. Porém o rendimento em físico-química, tanto na I quanto no início da II, mostrou-se insatisfatório. Os estudantes apresentavam postura passiva e usavam os livros do Ensino Médio. Apenas quatro acadêmicos conseguiram média em físicoquímica I em 2014, o restante reprovou e desenvolveu medo e inibição para com os docentes e a disciplina, segundo relatos dos mesmos. Em nenhum momento refletiram sobre a necessidade de melhorar seu conhecimento prévio de química, matemática e física para o entendimento dos conteúdos de físico-química.

Justificando o baixo desempenho, os acadêmicos reclamaram do Ensino Médio precário em escolas sem infraestrutura, com professores não habilitados na área das Ciências Exatas. A maioria escolheu o curso de química por falta de opção. A turma iniciou no segundo semestre de 2012 com 40 estudantes e no primeiro semestre de 2015 possuía apenas 12 acadêmicos dos ingressantes iniciais, os demais eram de outras turmas.

Quanto às dificuldades, forma e horas de estudo, percebeu-se que estudavam de forma errada, não faziam as listas por não conseguirem acompanhar as aulas e tentavam decorar os conteúdos. Então, além da mudança na metodologia era necessário ensinar cada 
acadêmico a estudar; a participar da construção do seu conhecimento, a abandonar velhos hábitos, a se motivar em resolver as listas; a questionar suas dúvidas e a usar os livros universitários ao invés das aulas do You Tube e livros do Ensino Médio apenas.

O objetivo didático das listas de exercícios não era atingido porque a maioria dos acadêmicos não as resolvia e também não questionava as dúvidas durante as aulas expositivas e dialogadas, pois, deixava para estudar poucos dias antes da avaliação, apesar da insistente orientação para que não levassem dúvidas para casa e que a dúvida de um poderia ajudar a responder a dúvida do outro. Porém não questionavam por não saberem o que perguntar, uma vez que não sabiam o conteúdo por falta de estudo. Sendo assim, não acompanhavam o raciocínio nem a resolução dos exemplos e dos problemas no quadro, as dúvidas surgiam no momento da avaliação, causando frustração e aversão pela disciplina.

Houve a necessidade de revisão dos conteúdos de química e matemática do Ensino Médio antes de aprofundar no aporte teórico do nível universitário, configurando como um fator limitante, pois, consumiu tempo, planejamento e horas a mais de aulas no contra turno.

\section{Cinética Química}

A princípio seria uma avaliação por unidade valendo 100 pontos e as listas seriam apenas para auxiliar no estudo, mas pelos resultados insatisfatórios da primeira avaliação (Quadro 1, coluna A1) elaborou-se uma sequência diferente para o conteúdo de cinética química, a fim de motivar os acadêmicos a estudarem. Nessa sequência, os acadêmicos apresentaram o seminário individual de 20 minutos antes do experimento, valendo 30 pontos. A temática do seminário era "Cinética Química”. Observou-se que apresentaram o conteúdo de forma muito rápida, geralmente em 10 minutos, a maioria não entendeu a proposta e acabaram escolhendo um tópico dentro do conteúdo de cinética para expor, pois acharam pouco tempo para uma aula completa. Infelizmente esse fato só foi percebido no momento dos seminários, e a forma de avaliação teve que ser revista para não prejudicar os critérios que seriam transformados em valores numéricos. Dos 17 acadêmicos, apenas 15 participaram da primeira sequência, pois, uma acadêmica estava de atestado médico e a outra conseguiu média igual a 70 na primeira avaliação e não quis fazer nova avaliação. Dos 15 acadêmicos, sete usaram apresentação em Power Point; três usaram o quadro e o pincel; dois não se sentiram aptos para a apresentação oral; três faltaram no dia da apresentação. A acadêmica que estava de licença retornou para a sala de aula e fez a avaliação substituta da primeira unidade e os que não apresentaram ou faltaram, tiveram uma nova chance e apresentaram em data posterior. As correções e sugestões foram feitas ao final de todas as apresentações, inclusive com sugestões dos estudantes.

Os acadêmicos entregaram por escrito uma autoavaliação e um comentário dos prós e contras da proposta. O objetivo do seminário foi de forçar o estudo, a leitura, o raciocínio e o 
discernimento entre os tópicos mais importantes do conteúdo; treinar e desinibir a oralidade; mostrar que precisavam intensificar e aprofundar os estudos, inclusive relembrar o conhecimento de matemática, português, física e química do ensino médio.

A aula prática em dupla envolveu a apresentação de um experimento que poderia ser modificado para se tornar inédito, adaptado de alguma referência, valendo 20 pontos. Como forma de incentivo, o desafio era que quem conseguisse modificar o experimento de forma adequada alcançaria a totalidade dos pontos. Essa etapa objetivou reforçar o entendimento do conteúdo teórico, aprofundar os estudos, incentivar a leitura e a pesquisa. Das oito duplas formadas, apenas três fizeram algum tipo de modificação nos experimentos de cinética e uma dupla apresentou um jogo de cartas, intitulado "jogo Quí-Mico" (Adaptado da referência disponível em <http://annq.org/eventos/upload/ 1330111341.pdf.> Acessado em 26 abr. 2015), incentivando toda a turma jogar (Figura 1). Os acadêmicos acharam o jogo muito interessante porque serviu para revisar o conteúdo de forma divertida, além disso, é um jogo versátil que serve para qualquer conteúdo.

A avaliação escrita substituta A1' (Quadro 1), também ocorreu com consulta e seu objetivo foi o de verificar a aprendizagem, substituir a primeira avaliação, amenizar o desafeto pela disciplina, mostrar que os acadêmicos são capazes de aprender os conteúdos que achavam impossíveis, desde que estudassem corretamente. O Quadro 1 traz os valores numéricos das diferentes formas de avaliação aplicadas para o conteúdo de cinética química. Os acadêmicos estão apresentados por algarismos indo-arábicos (IFRAH, 1997) de um a 16. É importante lembrar que no caso de o estudante não ter todas as avaliações (S1, E1, A1, A1'), prevaleceu o conceito obtido na avaliação A1', conforme ilustra o Quadro 1.

Quadro 1: Conceitos das avaliações realizadas em Cinética Química.

\begin{tabular}{|c|c|c|c|c|c|c|}
\hline Acadêmico(a) & A1 & S1 & E1 & C1 & A1' & $\begin{array}{c}\text { CF = A'1 ou C1 } \\
\text { ou }\left\{\left(\mathrm{S}_{1}+\mathrm{E}_{1}+\mathrm{A}^{\prime} 1\right) / 3\right\}\end{array}$ \\
\hline $\mathrm{O1}^{*}$ & $*_{-}$ & $*_{-}$ & $*_{-}$ & $*_{-}$ & 81,6 & 81,6 \\
\hline 02 & 15,0 & - & 75,0 & 30,0 & 64,5 & 64,5 \\
\hline 03 & 43,0 & 60,0 & 100 & 67,7 & 64,5 & 74,8 \\
\hline 04 & 35,0 & 50,0 & 50,0 & 45,0 & 53,0 & 53,0 \\
\hline 05 & 70,0 & - & 100 & 70,0 da A1 & 87,5 & 87,5 \\
\hline 06 & 47,0 & 53,0 & 100 & 66,7 & 69,5 & 74,2 \\
\hline 07 & 35,0 & 77,0 & - & 37,3 & 87,0 & 87,0 \\
\hline 08 & 55,0 & 57,0 & 100 & 70,7 & 44,5 & 70,7 \\
\hline 09 & 42,1 & 73,0 & 100 & 71,7 & 42,0 & 71,7 \\
\hline 10 & 43,0 & - & 100 & 47,7 & 94,5 & 94,5 \\
\hline 11 & 13,0 & 63,0 & 75,0 & 50,3 & 42,0 & 60,0 \\
\hline 12 & 5,0 & 50,0 & 90,0 & 48,3 & 42,0 & 60,7 \\
\hline 13 & 0,0 & - & 100 & 33,3 & 69,5 & 69,5 \\
\hline 14 & 25,0 & 53,0 & 75,0 & 51,0 & 39,5 & 55,8 \\
\hline 15 & 57,0 & - & 100 & 52,3 & 62,5 & 62,5 \\
\hline 16 & 5,0 & 57,0 & 75,0 & 45,7 & 39,5 & 57,2 \\
\hline 17 & - & 53,0 & 90,0 & 47,7 & 70,6 & 71,2 \\
\hline
\end{tabular}

Fonte: Autores 
O índice 1 indica primeira unidade; * licença médica; A1 = avaliação; A1’= avaliação substituta; $\mathrm{S} 1$ = seminário; $\mathrm{E} 1$ = experimento; $\mathrm{C} 1$ = conceito da primeira unidade; $\mathrm{CF}=$ conceito final [(A1’ $+\mathrm{S} 1+\mathrm{E} 1) / 3]$. Todas as atividades valiam 100 pontos.

Analisando o Quadro 1, comparando a primeira avaliação escrita (A1) com a avaliação após a aplicação da sequência (A1'), ficou notória a recuperação dos acadêmicos, pois antes apenas o estudante $\mathrm{n}^{\circ} \mathrm{O} 5$ havia conseguido atingir a média de 70,o e após a sequência outros oito acadêmicos conseguiram médias maiores ou iguais a 70,o (que é o valor estipulado pela UERR). Os demais conseguiram melhorar bastante seu desempenho, apesar de ficarem abaixo da média exigida no curso.

A seguir são transpostos alguns comentários a partir das autoavaliações, exatamente como os estudantes escreveram:

"Os seminários foram muito produtivos. Compreendi melhor o assunto e a explicação dos colegas. Para mim foi a melhor aula até hoje. Eu estava encanada sobre o assunto, pois acreditava que seria repetitivo e percebi que estava errada, pois, ninguém é igual”.

"Com o seminário foi possível ter outra visão do assunto e ter noção onde foi o erro de ter ido mal na $1^{\mathrm{a}}$ unidade e a falta de atenção na prova".

"O seminário foi proveitoso pelo fato de ter esclarecido muitas dúvidas inclusive na interpretação dos gráficos. Pra mim foi bom porque me fez arrumar um tempo no meio de tantos afazeres para estudar... Vi que sou capaz de superar meus limites, gostaria que os seminários continuassem, pois pra mim é o empurrão que eu precisava".

“... escolhi a parte que eu não tinha entendido e agora eu aprendi. Não tem nada melhor do que ter a consciência de que eu aprendi ..."

"A ideia do seminário é ótima, pois instiga o aluno a corrigir seus erros e buscar respostas para suas próprias dúvidas".

“... percebi que falta mais dedicação de todos em relação aos estudos ... de um modo geral e não só de físico-química".

“... não entendia e empurrava as dúvidas com a barriga, tentava resolver os exercícios sem relacionar com a teoria".

Pela fala dos acadêmicos é possível notar que perceberam que são capazes e que o maior problema era o fato de não saberem estudar. Ficaram maravilhados com os resultados e isso renovou o ânimo para a segunda unidade.

Os estudantes apresentaram dificuldades na interpretação, leitura e elaboração dos gráficos de cinética. Tal fato também ocorreu nos diagramas de fase e propriedades coligativas na Físico-Química I, indicando a necessidade de melhor trabalhar esses aspectos.

No final dessa sequência, perceberam que o problema estava neles por não saberem estudar e por recorrentes hábitos errados, como: estudar apenas antes da prova, não resolver as listas, copiar do colega, faltar e não pegar o que foi passado, insistência na postura de decorar sem entender, preguiça de ler e pensar, de acordo com a fala deles em suas autoavaliações.

Os estudantes apresentaram experimentos diversos, a saber: a) comprimido efervescente dissolvido em água quente, gelada e na temperatura ambiente para demonstrar a influência da temperatura e comprimido efervescente inteiro e triturado dissolvido em água à temperatura ambiente para mostrar a influência da superfície de contato; b) influência do catalisador de iodeto de potássio na decomposição da água oxigenada, utilizando esta última na forma diluída e a 30 volumes para mostrar também a influência da concentração; c) ISSN 2526-2882 
combustão da sacarose através da reação entre o bicarbonato de sódio, açúcar e álcool, intitulado "Serpente do Faraó", disponível no site do Ponto Ciência; d) Montagem de um extintor de incêndio utilizando garrafa de refrigerante, vinagre, bicarbonato de sódio; e) Jogo Qui-Mico adaptado com os conteúdos de Cinética Química; f) comportamento da enzima catalase em fatias de batata crua e água oxigenada. Alguns experimentos estão apresentados na Figura 1.

Figura 1: Experimentos de Cinética Química

(a)

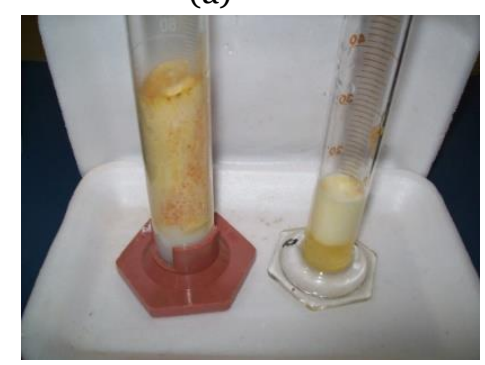

(c)

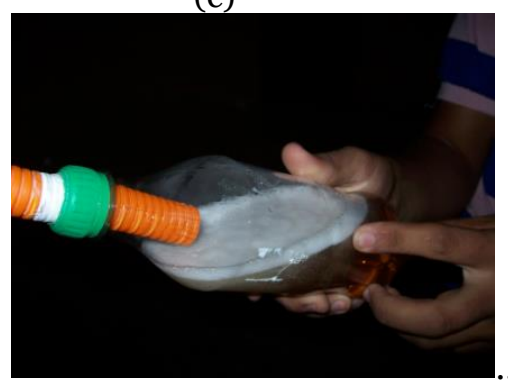

(b)

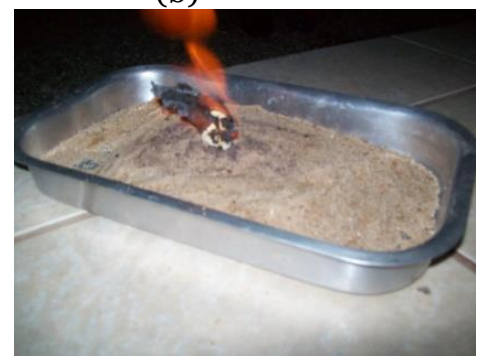

(d)

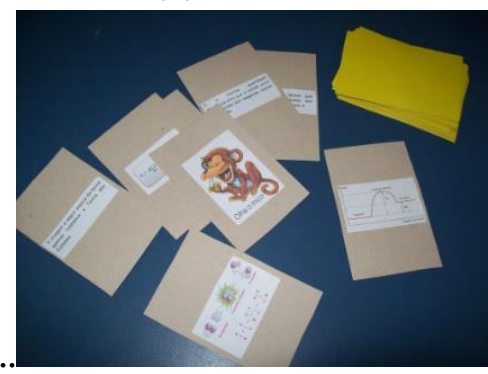

Fonte: Autores

a) Influência do catalisador de iodeto de potássio na decomposição da água oxigenada;

b) Combustão da sacarose através da reação entre o bicarbonato de sódio, açúcar e álcool, intitulado "Serpente do Faraó".

c) Construção de um extintor de incêndio a partir de vinagre, bicarbonato de sódio; d) Jogo Qui-Mico sobre Cinética Química. Fonte: Arquivo pessoal.

\section{Equilíbrio Químico}

Para o equilíbrio químico, os acadêmicos apresentaram o experimento antes da aula teórica, observou-se que utilizaram 20 minutos ou mais para expor toda a teoria. Os experimentos foram mais elaborados em comparação aos de cinética. Uma acadêmica ministrou sua aula utilizando quadro, pincel e resumo escrito no caderno de anotações, o restante utilizou recurso multimídia (slides em Power Point). O objetivo de o experimento ocorrer antes do seminário foi de facilitar a compreensão do conteúdo e motivar o aprendizado, uma vez que os experimentos sempre aguçam a curiosidade para entender o que está acontecendo. Observou-se também que o experimento antes da aula contribuiu no sentido de que os forçou a estudar mais para preparar a aula experimental com reagentes acessíveis, vidrarias disponíveis e materiais alternativos de baixo custo.

As demais etapas, seminário e avaliação, tiveram os mesmos objetivos descritos em cinética. As correções e sugestões foram feitas após cada apresentação e assim os acadêmicos 
foram percebendo seus erros e acertos. Comentaram que, apesar dos primeiros ficarem prejudicados, pois os últimos vão melhorando seus seminários ao longo da apresentação dos colegas, essa forma foi melhor para o aprendizado e percepção dos erros. O Quadro 2 mostra os conceitos obtidos na segunda unidade.

Quadro 2: Conceitos das avaliações realizadas em Equilíbrio Químico

\begin{tabular}{|c|c|c|c|c|}
\hline Acadêmico & A2 & E2 & S2 & C2 $=(\mathbf{A 2 + E 2 + S 2 / 3 ) ~}$ \\
\hline 01 & 73,8 & 100 & 100 & 91,3 \\
\hline 02 & 73,8 & 90,0 & 80,0 & 81,3 \\
\hline 03 & 61,3 & 95,0 & 85,0 & 80,4 \\
\hline 04 & 51,9 & 90,0 & 80,0 & 74,0 \\
\hline 05 & 95,6 & 100 & 98,0 & 97,9 \\
\hline 06 & 61,3 & 95,0 & 97,0 & 84,4 \\
\hline 07 & 83,1 & 100 & 98,5 & 93,9 \\
\hline 08 & 42,5 & 95,0 & 85,0 & 74,0 \\
\hline 09 & 42,5 & 95,0 & 75,0 & 70,8 \\
\hline 10 & 67,5 & 100 & 87,0 & 84,8 \\
\hline 11 & 51,9 & 95,0 & 90,0 & 79,0 \\
\hline 12 & 39,4 & 100 & 85,0 & 74,8 \\
\hline 13 & 45,6 & - & 93,0 & $69,3^{*}$ \\
\hline 14 & 39,4 & 95,0 & 90,0 & 74,8 \\
\hline 15 & 70,6 & 100 & 90,0 & 86,9 \\
\hline 16 & 39,4 & 90,0 & 85,0 & 71,5 \\
\hline 17 & 48,8 & 90,0 & 75,0 & 71,3 \\
\hline
\end{tabular}

$\mathrm{O}$ índice 2 indica segunda unidade; $\mathrm{A}=$ avaliação; $\mathrm{E}=$ experimento; $\mathrm{S}=$ seminário; $\mathrm{C}=$ conceito final [(A+S + E)/3]. * Nesse caso a média foi feita somando-se A2 + S2 e dividindo-se por 2.

A partir do Quadro 2 é possível notar uma melhora muito satisfatória em todos os acadêmicos. Destaque para o(a) acadêmico(a) 13 que não apresentou seminário na primeira unidade por uma crise recorrente de pânico ao falar em público. Em depoimento na sala de aula, os colegas da turma comentaram que o(a) referido(a) acadêmico(a) sempre se esquivava dos seminários e de tudo que envolvia apresentação oral; e que se surpreenderam positivamente com sua superação e esforço, e por conta disso a professora fez a média usando A2 e S2.

A turma se mostrou mais madura e unida, estudando juntos e se ajudando. Um comentário interessante de um dos acadêmicos: ..."antes cada um se isolava em seu canto e agora até nos confraternizamos em festas de aniversário e outras comemorações”. Os acadêmicos sugeriram em suas falas e avaliação da sequência que futuramente a professora colocasse o seminário junto com a aula experimental, pois achavam que ficaria mais fácil de explicar a teoria mostrando o experimento, porém a duração de cada aula teria que ser maior, talvez uma hora por dupla. Essa percepção foi muito interessante e mostrou um caminho para melhorar o processo de ensino e aprendizagem desse conteúdo específico. A seguir, alguns comentários da autoavaliação:

“... gostei mais desse experimento do que do primeiro ... vou estudar mais a linguagem química ... gosto de fazer experimentos, sai um pouco da teoria tradicional”. 
“... tivemos dificuldades para fazer as adaptações no experimento devido a dificuldade em achar os reagentes ...

“... não senti dificuldade em elaborar os slides e ajudou bastante para compreender os conteúdos".

“... durante o seminário dos colegas senti somar os conhecimentos e aprendi o que estava com dúvidas”.

“... percebi que por falta de estudo eu tinha dúvidas”.

“... os experimentos ajudam a entender como a reação acontece ... uma dificuldade é ter disciplina nos momentos de estudo (leitura)".

"... foi muito bom ver o interesse da professora e a reação de satisfação que causamos nela ... me sinto vencedora e capaz de conseguir ... agora vi que laboratório é minha paixão, vou continuar. Amei”.

Os experimentos incluíram: a) reação do permanganato com vinagre e diferentes concentrações de água oxigenada; b) reação entre o bicarbonato de sódio $\mathrm{NaHCO}_{3}$, presente em comprimidos efervescentes, e água, originando os íons $\mathrm{Na}^{+}$e $\mathrm{HCO}_{3}^{-}$, os quais em presença de água formam o íon hidroxila $\mathrm{OH}^{-}$, que deixam a solução com a coloração rosada, e o ácido carbônico $\left(\mathrm{H}_{2} \mathrm{CO}_{3}\right)$ que se decompõe, formando gás carbônico $\left(\mathrm{CO}_{2}\right)$; c) reação entre iodo sólido com vinagre e água sanitária; d) reação entre sulfato de cobre II e hidróxido de sódio gerando um equilíbrio heterogêneo; e) reação entre hidróxido de sódio, glicose e azul de metileno; f) efeito do íon comum usando água, bicarbonato de sódio e azul de bromotimol, em um aparato alternativo construído pela dupla a partir de cartucho de impressora, tripé adaptado de cabide, mangueira de soro, escalpe de soro e seringa contendo vinagre. A Figura 2 mostra alguns desses experimentos.

(a)

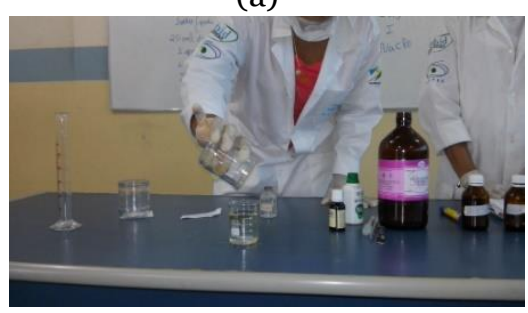

(b)

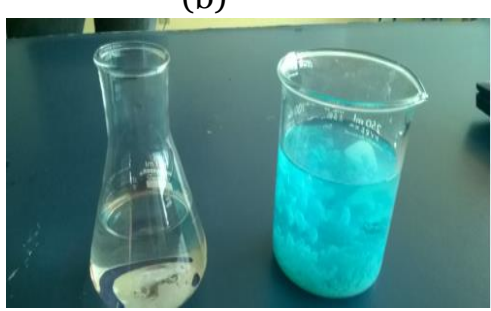

Fonte: Autores

a) Princípio de Le Chatelier - Reação entre o iodo sólido com vinagre e também adicionando água sanitária na mistura obtida. Inspirado na reação do permanganato de potássio com vinagre e água oxigenada do site do Manual do Mundo (http://www.manualdomundo.com.br/);

b) Equilíbrio heterogêneo, onde a reação entre sulfato de cobre II e hidróxido de sódio forma o precipitado de hidróxido de cobre II, presente no site do Ponto Ciência. Fonte: Arquivo pessoal.

Os experimentos são simples, porém possuem muitos detalhes e podem enriquecer as aulas sobre equilíbrio químico. O experimento da Garrafa Azul ou Água Furiosa, utilizando hidróxido de sódio, glicose e azul de metileno, é um experimento muito visual e interessante, capaz de aguçar a curiosidade para entender o que acontece, uma vez que em repouso a água fica transparente e quando agitada, fica azul. Nesse experimento a glicose reage com o azul de metileno, transformando-o em leucometileno que em repouso fica transparente, mas quando agitada, o oxigênio do ar se dissolve na água, reage com o leucometileno e faz com que o azul volte a ser a cor predominante (MANUAL DO MUNDO, 2013). Foi muito difícil encontrar 
glicose na cidade, mas os estudantes foram até o hospital para conseguir um pouco do reagente e o experimento deu muito certo, interessando a todos.

\section{Eletroquímica}

Nessa sequência, os acadêmicos apresentaram o experimento junto com o seminário, conforme sugestão de um deles, com o objetivo de melhorar a desenvoltura nas explicações, que ainda estavam fracas na segunda unidade. Os acadêmicos fizeram suas apresentações antes da aula teórica da professora e essa decisão foi tomada ao analisar a fala de uma acadêmica na segunda avaliação: “... o assunto não é tão fácil quando apresentado pela professora porque não temos nenhuma base antes ...”.

As diferentes etapas tiveram os mesmos objetivos já descritos anteriormente. O Quadro 3 apresenta os conceitos obtidos na terceira unidade e o conceito final da disciplina. Quem não apresentou seminário, ficou apenas com o conceito da avaliação escrita.

Quadro 3:Conceitos das avaliações realizadas em Eletroquímica e o conceito final das três unidades $\left(\mathrm{C}_{\mathrm{F}}\right)$.

\begin{tabular}{|c|c|c|c|c|}
\hline Acadêmico(a) & $\mathbf{S 3}+\mathbf{E} 3$ & A3 & $\begin{array}{c}\mathrm{C}_{3}=\mathrm{A}_{3} \text { ou } \\
\left\{\left(\mathrm{S}_{3}+\mathrm{E}_{3}\right)+\mathrm{A} 3 / 2\right\}\end{array}$ & $\mathrm{C}_{\mathrm{F}}=\left(\mathrm{C}_{1}+\mathrm{C}_{2}+\mathrm{C}_{3} / 3\right)$ \\
\hline 01 & 90,0 & 77,0 & 83,5 & $81,6+92,3+83,5 / 3=85,5$ \\
\hline 02 & 75,0 & 97,6 & 86,3 & $64,5+81,3+86,3 / 3=77,4$ \\
\hline 03 & - & 79,0 & 79,0 & $74,8+80,4+79,0 / 3=78,1$ \\
\hline 04 & 75,0 & 83,0 & 83,0 & $53,0+74,0+83,0 / 3=70,0$ \\
\hline 05 & 100 & 100 & 100 & $87,5+97,9+100 / 3=95,1$ \\
\hline 06 & 80,0 & 55,0 & 68,0 & $74,2+84,4+68,0 / 3=75,5$ \\
\hline 07 & - & 100 & 100 & $87,0+93,9+100 / 3=93,6$ \\
\hline 08 & 70,0 & 61,0 & 66,0 & $70,7+74,0+66,0 / 3=70,2$ \\
\hline 09 & 70,0 & 75,4 & 70,2 & $71,7+70,8+70,2 / 3=70,9$ \\
\hline 10 & 85,0 & 100,0 & 92,5 & $94,5+84,8+92,5 / 3=90,6$ \\
\hline 11 & 80,0 & 100,0 & 90,0 & $60,0+79,0+90,0 / 3=76,3$ \\
\hline 12 & 85,0 & 92,0 & 88,5 & $60,7+74,8+88,5 / 3=74,7$ \\
\hline 13 & 82,0 & 68,0 & 75,0 & $69,5+69,3+75,0 / 3=71,3$ \\
\hline 14 & 76,0 & 97,6 & 86,8 & $55,8+74,8+86,8 / 3=72,5$ \\
\hline 15 & - & 100 & 100 & $62,5+86,9+100 / 3=83,1$ \\
\hline 16 & 80,0 & 86,5 & 83,2 & $57,2+71,5+83,2 / 3=70,6$ \\
\hline 17 & 75,0 & 86,5 & 80,7 & $71,2+71,3+80,7 / 3=74,4$ \\
\hline
\end{tabular}

Fonte: Autores

$\mathrm{O}$ índice 3 indica terceira unidade; $\mathrm{A}=$ avaliação; $\mathrm{E}=$ experimento; $\mathrm{S}=$ seminário; $\mathrm{C}=$ conceito final $\left[\left(\mathrm{A}_{3}+\mathrm{S} 3+\mathrm{E} 3\right) / 3\right] ; \mathrm{C}_{\mathrm{F}}=$ conceito final das unidades $\left[\left(\mathrm{C}_{1}+\mathrm{C}_{2}+\mathrm{C}_{3}\right) / 3\right]$.

Pelos resultados do Quadro 3, especialmente a coluna do Conceito Final $\left(\mathrm{C}_{\mathrm{F}}\right)$, observase que todos os acadêmicos conseguiram médias iguais ou superiores a 70, demonstrando que a metodologia alcançou os objetivos propostos.

A seguir, alguns comentários da autoavaliação após o seminário de eletroquímica: 
"Depois dos seminários ficou mais fácil fazer a prova, pois, ao nos preparar para o seminário a fim de dominar o conteúdo, absorvemos mais conhecimento".

"A prova estava fácil, faltou mais estudo. Aprendi a estudar com essa metodologia, pois, eu achava que sabia, mas descobri que não sabia estudar".

“... senti que melhorei, a prova estava fácil e trabalhosa, consegui responder...”.

"Foi difícil preparar um seminário de um assunto ainda não estudado, mas depois eu consegui entender a fala da professora porque eu já tinha me esforçado pra entender sozinha... "

“... me senti mais a vontade e mais preparada no assunto de eletroquímica para preparar o seminário e sei que vou conseguir tirar as dúvidas quando a professora for dar a aula... “.

Nenhum dos estudantes ficou de exame final e isso os incentivou para fazerem novamente a disciplina de Físico-Química I no segundo semestre de 2015 e dos 10 acadêmicos que cursaram a referida disciplina, nove passaram sem ficar de exame final, uma desistiu por problemas de saúde, e comentaram que o conhecimento de físico química II auxiliou a entenderem algumas questões em Físico-Química I. Esse fato mostrou que aprenderam a estudar para reter o conhecimento, mudando o hábito de decorar sem entender.

Os autores apontam que é uma satisfação para um professor saber que conseguiu fazer seus estudantes aprenderem e apreciarem o conhecimento. Pelas falas é possível notar o amadurecimento e a mudança de visão com a descoberta dos erros e dos caminhos para superarem as dificuldades, indicando que os objetivos propostos foram atingidos.

Os estudantes demonstraram diferentes experimentos, como: a) pilha feita com vários tomates; b) pilha feita com limão; c) reprodução da pilha de Daniel; d) pilha feita com duas metades de batata crua; e) eletrólise da água com a produção de gás hidrogênio e oxigênio.

Nos experimentos de pilha os fios de cobre foram adaptados em uma calculadora de bolso a fim de mostrar a passagem de corrente elétrica, ou a uma lâmpada de pisca-pisca (Mini Spot LED). Os estudantes apresentaram melhor desempenho na apresentação oral do que nos trabalhos escritos, indicando a necessidade de mais estudos de Língua Portuguesa.

\section{Forma de Avaliação dos Seminários}

De modo geral, os seminários foram avaliados pela professora da turma, levando-se em consideração alguns itens essenciais sugeridos por Silva (s.d.). Os itens adaptados e os critérios finais envolveram: didática (postura, voz audível, erros de português, erros conceituais, movimentação e manias, domínio do conteúdo, linha do tempo e apresentação dos tópicos principais e dos slides considerando o tamanho das letras e a quantidade de informação em cada um); tópicos abordados e não abordados, tempo utilizado, uso ou não de ficha de apoio, uso de exemplos e gráficos ou tabelas, contextualização, inovação nos experimentos, normas da ABNT, referências utilizadas. Cada item contava um ponto, e o total era comparado com uma lista de tópicos elaborada pela professora com base nos livros sugeridos e com o que foi trabalhado em sala de aula. O número máximo contido na lista equivalia a 100 pontos e por regra de três simples chegava-se ao valor numérico alcançado pelo estudante. Procedimento semelhante foi adotado para os planos de aula e a explicação dos experimentos. 
As avaliações escritas foram elaboradas de forma a conter perguntas abertas e fechadas, sempre acompanhadas de uma questão para o estudante expor sua opinião, crítica, sugestão, comentário e outra de autoavaliação. As perguntas relativas ao conteúdo continham certo número de acertos que equivaliam a 100 pontos e por regra de três simples chegava-se ao conceito alcançado pelo estudante. Apenas um estudante sempre se recusava a comentar ou dar opiniões, deixando as questões de cunho pessoal sem responder, dizendo que para ele era indiferente e que estava gostando da metodologia. Essas questões valiam pontos extras que o acadêmico deixou de ganhar.

Os dados mostraram que ao longo do processo, os acadêmicos conseguiram construir e conectar conhecimentos, aprenderam a buscar as informações e a rever assuntos necessários para o entendimento dos conteúdos. A melhor metodologia, na opinião dos autores, seria a união das sequências 2 e 3, onde os acadêmicos apresentariam o conteúdo trazendo um experimento ou dinâmica para auxiliar na aquisição dos termos e conceitos, seguida de um fechamento com a explicação do professor e a seguir, a complementação do estudo com uma lista de exercícios ou de resolução de problemas.

Esse estudo corrobora com as percepções de Colares et. al. (2011), Martins, Moura e Bernardo (2018), em que a sala de aula é um rico laboratório de pesquisa e que o professor deve ser um pesquisador-reflexivo que desenvolve a autocrítica e a capacidade de repensar sua prática pedagógica. Porém, percebemos com essa experiência, que tanto o professor quanto o licenciando precisam desenvolver o perfil pesquisador-reflexivo a fim de construir sua formação profissional permanentemente, problematizando os processos de ensino e de aprendizagem com a realidade em que estão inseridos.

\section{Considerações finais}

Os resultados foram satisfatórios e os objetivos foram alcançados, porém é importante ressaltar que essa metodologia é trabalhosa, requer tempo e a elaboração de critérios de avaliação. É um trabalho que requer a formação de licenciado por parte do professor e sua contínua atualização, pois mostra a necessidade de ensinar química de uma forma mais didática e com mais significado para o estudante, que na opinião dos autores é a tendência atual para todas as áreas do conhecimento.

O baixo rendimento dos acadêmicos estava associado ao fato de não estudarem de forma correta e descobriram ao longo do processo que não se dedicavam o tempo necessário para a aquisição do conhecimento. Amadureceram percebendo seus erros e acertos, se tornaram estudantes mais dedicados e competentes no semestre seguinte. Passaram a usar os livros universitários e a estudar um pouco por dia ao invés de poucos dias antes das avaliações.

A melhor sequência apontada pelos estudantes foi a última, do conteúdo de eletroquímica, porque os forçou a ir além de seus limites e conhecimentos para montar uma 
aula sobre algo que ainda não tinham visto. Na opinião dos autores as quatro sequências foram importantes, pois, cada uma teve sua contribuição, preparando-os para o desafio maior da última sequência. Desse modo a primeira mostrou a falha e uma possível solução; a segunda mostrou que a sequência poderia ser melhorada e a última mostrou que eles são capazes de estudar um conteúdo mesmo antes da explicação do professor e que isso os ajudou a melhor entender e sanar suas dúvidas durante a aula.

Essa forma diferenciada de avaliação foi aprovada pelos acadêmicos, porém, cabe ressaltar que funcionou para uma turma pequena e talvez tenha que sofrer alterações para ser aplicada em uma turma mais numerosa.

Os acadêmicos fortaleceram competências como argumentação, senso crítico, percepção entre os aspectos teóricos e sociais que os levaram à mudança de atitude frente às demandas necessárias à sua formação como professores. É importante acrescentar que todos eles eram bolsistas do Projeto PIBID Química UERR Rorainópolis, na ocasião, e a presente pesquisa foi depois reproduzida por eles em seus estágios de docência.

Esse estudo mostrou a possibilidade de trabalhar conteúdos específicos da área das exatas de uma forma mais didática ao invés da aula puramente conteudista com memorização de algoritmos para a resolução de problemas estritamente numéricos.

\section{Referências}

BARDIN, L. Análise de Conteúdo. São Paulo: Edições 70, 2011.

BERGMANN, J.; SAMS, A. Sala de aula invertida: uma metodologia ativa de aprendizagem, $1^{\text {a }}$ ed. Rio de Janeiro: LTC, 2017. ISBN 978-85-216-3045-6.

CARVAlHO-OLIVEIRA, J. C. de; OllveirA, A. C. de. O ensino de química em Rorainópolis-RR entre 2007 e 2009. v. 4, n. 1, 2012. Revista Ambiente: Gestão e Desenvolvimento (REMGADS). ISSN: 1981-4127. Disponível em: $<$ uerr.edu.br/remgads $>$.

CHIZZOTTI, A. Pesquisa qualitativa em ciências humanas e sociais. 3. ed. Petrópolis: Vozes, 2010.

COLARES, M. L. I. S.; GONÇALVES, T. O.; CORARES, A. A.; LEÃO, J. P. P. O professorpesquisador-reflexivo: debate acerca da formação de sua prática. Olhar de professor, Ponta Grossa, v. 14, n. 1: p. 151-165, 2011. Disponível em <http://www.revistas2.uepg.br/index.php/olhardeprofessor/article/viewFile/3490/ 2508>. Acesso em 01 set. 2020.

JAIME, M. P.; KOLLER, M. R. T.; GRAEML, F. R. La aplicación de flipped classroom en el curso de dirección estratégica. In: JORNADAS INTERNACIONALES DE INNOVACIÓN UNIVERSITARIA EDUCAR PARA TRANSFORMAR, 12., 2015. Actas... Madrid: UNIVERSIDAD EUROPEA, 2015. p. 119-133. 
IFRAH, Georges. História Universal dos Algarismos - Tomo I. São Paulo: Editora Nova Fronteira. 1997, 738 p. ISBN 8520908411.

MARTINS, E. D.; MOURA, A. A.; BERNARDO, A. A. O processo de construção do conhecimento e os desafios de ensino-aprendizagem. RPGE - Revista on line de Política e Gestão Educacional, Araraquara, v. 22, n. 1, p. 410-423, jan/abr. 2018. Disponível em: $<$ https://periodicos.fclar.unesp.br/rpge/article/viewFile/10731/7347>. Acesso em 1 set. 2020.

OLIVEIRA, M. M. de. Sequência didática interativa no processo de formação de professores. Petrópolis, RJ: Vozes, 2013. ISBN 978-85-326-4472-5.

PRODANOV, C. C.; FREITAS, E. C. Metodologia do Trabalho Científico (recurso eletrônico): Métodos e técnicas da pesquisa e do trabalho acadêmico. $2^{\mathrm{a}}$ edição. Novo Hamburgo, RS: Universidade FEEVALE, 2013. ISBN 978-85-7717-158-3. Disponível em: <www.feevale.br/editora >.

SILVA, R. Seminários: Como avaliar diminuindo as injustiças? (sem data - s.d.) Disponível em: <www.ufac.br>. Acesso em 14 Abr. 2014.

TENÓRIO, I. Água furiosa. Manual do Mundo. Postado em 20 jun. 2013. Disponível em: $<$ https://manualdomundo.uol.com.br/2013/o6/experimento-de-quimica-da-aguafuriosa/>. Acesso em o3 mai. 2015.

\section{Agradecimentos}

Aos acadêmicos da Turma T6V/2015 do Curso de Licenciatura Plena da UERR Campus Rorainópolis.

\section{Biografia Resumida}

Josimara Cristina de Carvalho Oliveira: Bacharel em Química (1991), Licenciada em Química (1994), Mestre em Química (1995) e Doutora em Química (2000) pela Universidade Estadual Paulista Júlio de Mesquita Filho - UNESP - Araraquara/SP. Área de concentração: Ensino de Química; Físico-Química; Ciências da Natureza e dos Materiais. Atuação: Universidade Estadual de Roraima - UERR Campus Rorainópolis. Av. Senador Hélio Campus s/n, centro. CEP: 69373-00o. Rorainópolis-RR, Brasil. Lattes: http://lattes.cnpq.br/1890754707891189

Contato:josi903@yahoo.com.br 
André Camargo de Oliveira: Bacharel em Química (1996), Mestre em Química Orgânica (1999) pelo Instituto de Química de Araraquara-Universidade Estadual Paulista Júlio de Mesquita Filho UNESP. Doutor em Ciências pela Universidade Estadual de Campinas-SP-UNICAMP (2005). Pós-doutor em Produtos Naturais pelo Instituto Nacional de Pesquisas da AmazôniaINPA (2007). Área de Concentração: Química Orgânica, Produtos Naturais Bioativos, Etnofarmacologia, Bioprospeccção, Métodos Cromatográficos, Estudo Fitoquímico, Caracterização Estrutural de Substâncias Bioativas, Ressonância Magnética Nuclear (RMN) uni e bi-dimensionais, Espectrometria de Massas, Ensaios farmacológicos. Atuação: Universidade Estadual de Roraima - UERR, Campus Rorainópolis. Av. Senador Hélio Campus s/n, centro. CEP: 69373-ooo. Rorainópolis-RR, Brasil.

Contato: acco9995@yahoo.com.br

Lattes: http://lattes.cnpq.br/1633357602206781 